\title{
Critical appraisal of the modified ante situm liver resection
}

\section{Is the original method the better choice?}

\author{
Mohammad H. Fard-Aghaie ${ }^{1,2} \cdot$ Alexandros Kantas $^{1,2} \cdot$ Georgios Makridis ${ }^{1,2} \cdot$ Tim Reese $^{1,2} \cdot$ Kim C. Wagner $^{1,2}$. \\ Karl J. Oldhafer ${ }^{1,2}$
}

Received: 26 March 2019 / Accepted: 28 May 2019 / Published online: 10 June 2019

(C) Springer-Verlag GmbH Germany, part of Springer Nature 2019

Dear Editor,

We congratulate the Hanover Group for their extraordinary results.

They showed that the ante situm liver resection can be safely performed in an experienced HPB center without hypothermia and veno-venous bypass [1]. However, we have some questions and comments:

Since we see an indication for the hypothermic perfusion to increase the ischemic tolerance in these long procedures, we are interested in the postoperative liver function tests in the described cohort.

In addition, we see the avoidance of the veno-venous bypass quite critically, taking into account the largest publication so far by Azoulay et al., which showed a 90-day mortality of $19.5 \%$ in 77 patients treated with in situ hypothermic perfusion and bypass [2].

Reflected by the data of the present study, only 2 of 8 patients received a complete inferior vena cava (IVC)-replacement. According to our data of 12 consecutive cases of either ante situm or in situ resections with bypass and hypothermia, we did not experience any mortality. Thus, we firmly believe that the time-consuming phase, which may pose difficulties for the surgeon, arises not during the resection, but during the reconstruction of the IVC and the venous outflow. The abandoned techniques might alleviate this time pressure.

Furthermore, the statement "...preferred to be prepared to initiate cold perfusion..." remains unclear and we would like to know your concrete indications for starting a cold perfusion

Mohammad H. Fard-Aghaie

m.fard@asklepios.com

1 General and Abdominal Surgery, Asklepios Hospital Barmbek, Ruebenkamp 220, 22291 Hamburg, Germany

2 Medical Faculty, Semmelweis University, Asklepios Campus Hamburg, Hamburg, Germany during the ongoing procedure. In our hands, we prefer to start with cold perfusion/bypass in all patients eligible for an ante situm resection with expected reconstruction of the IVC and venous outflow in order to increase safety.

Finally, we agree that not all in situ operations need to be performed with veno-venous bypass, since a reconstruction of the IVC and/or the ante situm position are not always necessary. We would like to ask the authors to balance the possible side effects of the bypass and/or cold perfusion with the $19.5 \%$ liver insufficiency rate reported by Azoulay et al. [2]

We thank the Hanover group for their outstanding paper and the initiation of this very interesting discussion.

\section{Compliance with ethical standards}

Conflict of interest The authors declare that they have no conflict of interest.

\section{References}

1. Oldhafer F, Ringe KI, Timrott K, Kleine M, Beetz O, Ramackers W, Cammann S, Klempnauer J, Vondran FWR, Bektas H (2018) Modified ante situm liver resection without use of cold perfusion nor veno-venous bypass for treatment of hepatic lesions infiltrating the hepatocaval confluence. Langenbeck's Arch Surg 403(3):379386

2. Azoulay D, Lim C, Salloum C, Andreani P, Maggi U, Bartelmaos T, Castaing D, Pascal G, Fesuy F (2015) Complex liver resection using standard total vascular exclusion, venovenous bypass, and in situ hypothermic portal perfusion: an audit of 77 consecutive cases. Ann Surg 262(1):93-104

Publisher's note Springer Nature remains neutral with regard to jurisdictional claims in published maps and institutional affiliations. 